\title{
Oral Radiology adopts an innovative system for online submission, editorial processing, and publication
}

\author{
Keiji Tanimoto
}

Published online: 16 October 2009

(C) Japanese Society for Oral and Maxillofacial Radiology and Springer 2009

Oral Radiology (OR), the official English-language journal of the Japanese Society for Oral and Maxillofacial Radiology (JSOMR), was first published in 1985. At that time Dental Radiology (DR; Shikahoushasen), the official Japanese-language journal of JSOMR, had issued 25 volumes. Although DR published a number of valuable papers, many foreign researchers asked why we did not publish them in English, as Japanese was little understood outside of Japan. At that time, most Japanese researchers felt that English was a difficult language to use, and very few of them could submit papers to English-language journals. For that reason, the directors of JSOMR decided to support the English publications of JSOMR members by establishing OR. Professor Hajime Fuchihata of Osaka University, the first editor of OR, worked very hard to achieve that goal. Since then, OR has published two issues annually and has helped JSOMR members to write papers in English. Japanese researchers subsequently have become more confident about publishing their work in English.

I became the editor of Oral Radiology in 2002, succeeding the second editor of OR, Professor Kanji Kishi of Okayama University. I believed that it was the time to support oral radiologists in Asian countries by publishing their papers. This was the first mission I set for us. Another mission for OR was to make it a truly international journal, because at that time most of the papers submitted were from JSOMR members. With that in mind, we began accepting submissions from researchers worldwide, without requiring membership in JSOMR. Recently, submissions from Asia, the Middle East, and other parts of the world have surpassed those from Japan, and the total number of submissions has more than doubled. Beginning in 2008, OR has been indexed in Science Citation Index Expanded. I believe that OR now has become a well-recognized international journal in the field of oral and maxillofacial radiology.

Now is the time to introduce a new system for online submission, editorial processing, and publication. Procedures for submission, editorial processing and publication will change radically as of March 2010. Changes in the system are one thing, but a truly innovative change is that dynamic images can be provided on the website. It has become possible to show not only ultrasonography but also 3-D movies incorporating CT and MR images, which facilitate readers' understanding.

Now is also the time for you to submit your papers to Oral Radiology. Both new-type electronic papers, with dynamic imagery, and more conventional papers in digital format are welcomed. We greatly look forward to your submissions.

Keiji Tanimoto, DDS, PhD

Editor-in-Chief
K. Tanimoto $(\bowtie)$

Department of Oral and Maxillofacial Radiology,

Graduate School of Biomedical Sciences,

Hiroshima University, 1-2-3 Kasumi,

Minami-ku, Hiroshima 734-8553, Japan

e-mail: kg@hiroshima-u.ac.jp 